\title{
AXIAL LENGTH, CORNEAL CURVATURE AND THEIR ASSOCIATION WITH THE REFRACTIVE STATUS OF THE EYE
}

\author{
B. Karunakar1, Rajlingam², Lokabi Reddy³, Srinivas Murthy4, Srikanth ${ }^{5}$
}

${ }^{1}$ Associate Professor, Department of Ophthalmology, Sarojini Eye Hospital, Hyderabad. ${ }^{2}$ Associate Professor, Department of Ophthalmology, Sarojini Eye Hospital, Hyderabad. ${ }_{3}^{3}$ Associate Professor, Department of Ophthalmology, Sarojini Eye Hospital, Hyderabad. ${ }^{4}$ Associate Professor, Department of Ophthalmology, Sarojini Eye Hospital, Hyderabad. 5Post Graduate, Sarojini Eye Hospital, Hyderabad.

\section{ABSTRACT}

\section{AIM}

To establish a definite correlation between the axial length, radius of cornea curvature and the refractive status of the eye.

\section{METHODS}

All cases of emmetropia, myopia, hypermetropia, astigmatism between 20-30 years attending the Outpatient Department of Ophthalmology were informed about the purpose for the tests and the following were done. Visual acuity without and with correction, Subjective refraction, Fundus evaluation, Intraocular pressure, Keratometry. Ultrasound biometry to assess anterior chamber depth, lens thickness, axial length and vitreous chamber depth in all subjects in both eyes.

\section{RESULTS}

Correlation between SE (Spherical equivalent) and AL/CRC; AL (Axial length), and CRC (Corneal radius of curvature), the highest and lowest AL/CRC values were seen in eyes with high myopia and high hyperopia, respectively. Mean AL/CRC was 3.49 in eyes with myopia greater than -5.0D; this value decreased linearly and reached a minimum of 2.65 in cases with hyperopia more than $2.0 \mathrm{D}$. Linear regression showed a shift of 11.46D in SE refractive error towards myopia with every 1 unit increase in $A L / C R C(P<0.001)$.

\section{CONCLUSION}

Refractive error cannot be determined by a single optical component. It is the result of a combined interactive effect. The ratio of axial length and corneal radius of curvature seem to be a very reliable index of estimating the kind of resultant refractive error one might have. Axial length is the most influential factor in determining refraction radius curvature.

\section{KEYWORDS}

Axial Length, Corneal Radius of Curvature, Myopia, Hyperopia.

HOW TO CITE THIS ARTICLE: Karunakar B, Rajlingam, Reddy L, et al. Axial length, corneal curvature and their association with the refractive status of the eye. J. Evolution Med. Dent. Sci. 2016;5(10):422-426, DOI: 10.14260/jemds/2016/97

\section{INTRODUCTION}

Ocular biometrics are among the most important factors affecting refractive errors..$^{1-3}$ Most studies suggest Axial Length $(\mathrm{AL})$, is the most important determinant of refractive errors. ${ }^{2-}$ ${ }^{6}$ However, current knowledge on emmetropization indicates that individual biometric components are not important by themselves and that emmetropization is a result of a balance among these components. ${ }^{7}$ Changes in AL and Corneal Radius of Curvature (CRC) are important biometric factors affecting refractive errors. ${ }^{8-10} \mathrm{AL}$ has a larger effect on inducing refractive errors as compared to CRC.2,3

However, the process of emmetropization seems to indicate a compensating association between these two components. For example, Grosvenor et al. ${ }^{8}$ demonstrated a more important role for the AL/CRC ratio than for AL alone and the correlation between Spherical Equivalent (SE) refractive error and this variable was stronger than that with each of its components alone.

Financial or Other, Competing Interest: None.

Submission 27-09-2015, Peer Review 03-10-2015,

Acceptance 08-10-2015, Published 04-02-2016.

Corresponding Author:

Dr. B. Karunakar

13-9-121,

Panduranga Nagar, Hyderabad.

E-mail: bathula.karunakar814@gmail.com

DOI: $10.14260 /$ jemds/2016/97
Subsequently, other studies have shown that the AL/CRC ratio was the most important biometric factor in myopia, especially high myopia.10,11 AL/CRC was first studied by Emsley and later addressed in other studies. ${ }^{8}$ However, $\mathrm{AL} / \mathrm{CRC}$ has been less extensively studied than other biometric parameters. The average values reported for AL/CRC range from 2.90 to $3.10 .2,3,12,13$ Some reports have indicated that $\mathrm{AL}$ is smaller in some races despite a higher prevalence of myopia. This observation indicates that AL/CRC may be a more important factor than AL or CRC alone.

Few studies have studied this index in the Middle East.3,12,14 Although, in some areas of the world this index can be derived from studies on $\mathrm{AL}$ and $\mathrm{CRC}$, reports concerning $\mathrm{AL} / \mathrm{CRC}$ are scarce. Herein, we report the AL/CRC ratio in the population visiting Sarojini Devi Eye Hospital. We examine the correlation between this index and their association with refractive error.

\section{AIMS AND OBJECTIVES}

The aim of this study was to investigate the key components of refraction.

a. To know the alterations in each component for various refractive states of the eye.

b. To establish a definite correlation between the axial length, radius of cornea curvature and the refractive status of the eye. 


\section{MATERIALS AND METHODS}

The materials for the present study were taken from patients attending the Outpatient Department of Ophthalmology at Sarojini Devi Eye Hospital, Osmania Medical College, Hyderabad, from December 2012 to September 2014.

\section{Inclusion Criteria}

- All cases of emmetropia, myopia, hypermetropia, astigmatism between $20-30$ years.

\section{Exclusion Criteria}

- Pathological myopia.

- Lenticular opacities.

- Gross vitreous opacities.

Patients were informed about the purpose for the tests and the consent for the tests was taken. Both eyes were examined in detail using Zeiss slit lamp to look for any other associated ocular abnormality. Visual acuity without and with correction were studied using Snellen's acuity chart. Subjective refraction will be done following cycloplegic retinoscopy to objectively assess degree of refractive error. Fundus evaluation was done using direct and indirect ophthalmoscopy to look for degenerative changes. Intraocular pressure was measured using applanation tonometry to rule out associated primary open angle glaucoma. Keratometry was done to measure corneal curvature using Bausch and Lomb keratometer. Ultrasound biometry was using contact probe biomedix with digital display to assess anterior chamber depth, lens thickness, axial length and vitreous chamber depth in all subjects in both eyes. The velocity of sound was adjusted for different media as follows: Cornea $(1641 \mathrm{~m} / \mathrm{sec})$, aqueous/vitreous $(1532 \mathrm{~m} / \mathrm{sec})$, lens $(1641 \mathrm{~m} / \mathrm{sec})$. Acceptable reading was defined as set of recordings, which had an $\mathrm{SD}<0.2$.

Statistical Analyses were done using the Following Formulae

$$
\text { Mean }=\frac{\text { sum of all values }}{\text { number of values }}
$$

Regression analysis was done and $\mathrm{R}$ co-efficient was computed.

\section{RESULTS}

Of the 300 eligible subjects, 296 individuals (98.66\%) agreed to participate. For the purpose of the current study, we eliminated data from 4 individuals who had missing data. Eventually, analysis was performed on data from 271 patients. Considering the high correlation between fellow eyes in terms of AL ( $\mathrm{r}=\mathrm{xyz})$ and $\mathrm{CRC}(\mathrm{r}=\mathrm{abc})$, only data from right eyes are presented.

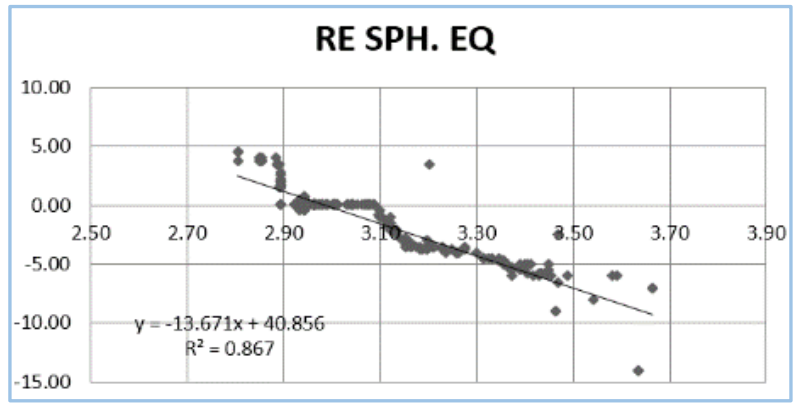

Fig. 1: Linear Regression between $A L / C R C$ and Spherical Equivalent in Right Eye

The linear regression equation showing that for every 1 unit increase in the ratio of AL and CRC will cause nearly a 14D shift towards myopia. The R2 of 0.867 shows that there is $86.7 \%$ chance that the variation of the spherical equivalent can be explained by the variation of the ratio between AL and CRC in the right eye.

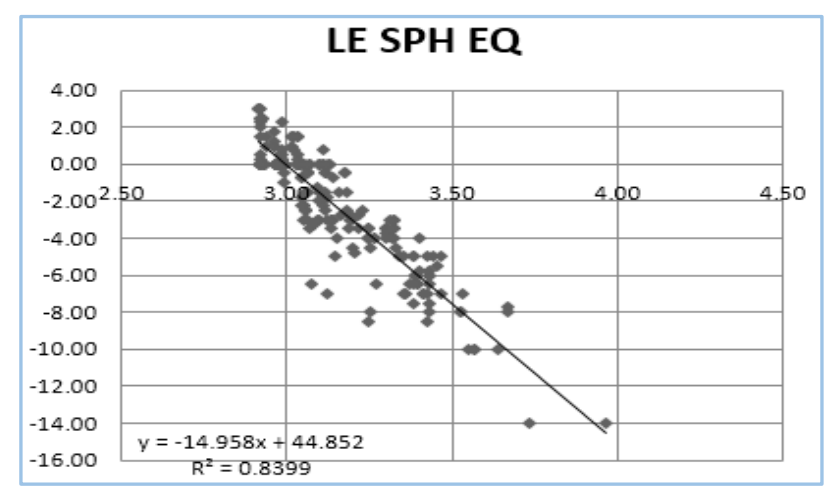

Fig. 2: Linear Regression between $A L / C R C$ and Spherical Equivalent in Left Eye

Similar findings have been observed in the LE, where 1 unit rise in the ratio of AL and CRC leads to a shit of 15 diopters towards myopia. R2 coefficient of 0.839 shows that there is $83.9 \%$ chance of explaining the variation of the spherical equivalent with the variation of the ratio between AL and CRC. This finding is similar to that observed in the RE.

\section{Mean CRC Vs. RE Spherical Equivalent}

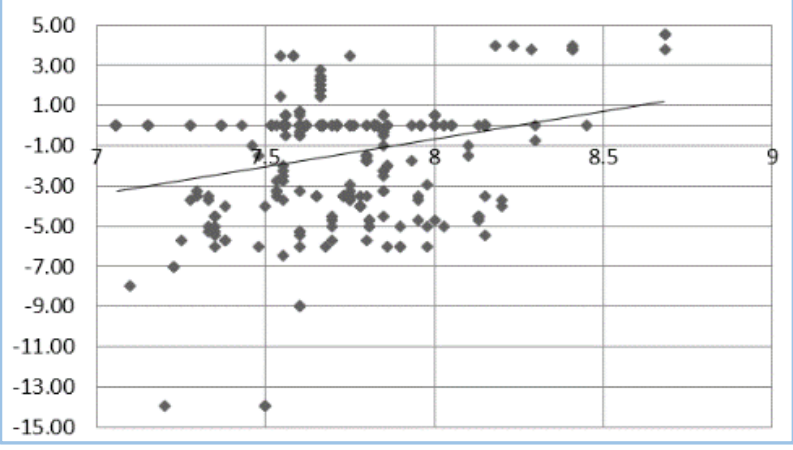

Fig. 3: Scatter Graph showing relationship between Mean CRC and Spherical Equivalent in Right eye

The regression analysis done for the variations between axial length and spherical equivalent showed an $\mathrm{R}^{2}$ coefficient of 0.694 , which means a $69.4 \%$ chance exists to explain the interdependent variation of the variables. The $\mathrm{R}^{2}$ for mean CRC and spherical equivalent is xyz. 
This signifies that the variation is better correlating the ratio of the $\mathrm{AL}$ and $\mathrm{CRC}$ rather than their independent variations, although axial length correlates better than mean CRC.

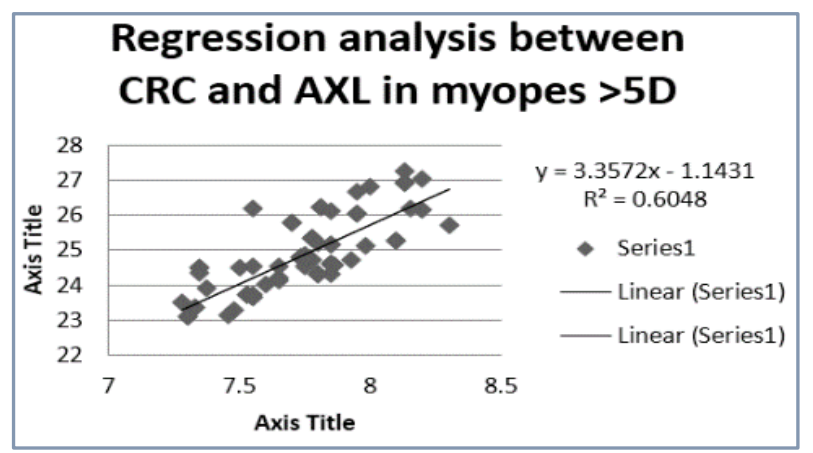

The linear regression between CRC and AXL in myopes $>5 \mathrm{D}$ showed that every 1 unit increase in CRC was associated with an increase in the axial length by $3.3 \mathrm{~mm}$ with an R2 of 0.604 indicating that there was a $60.4 \%$ chance to explain this relation. The radius of curvature ranging from 7.2 to 8.3.

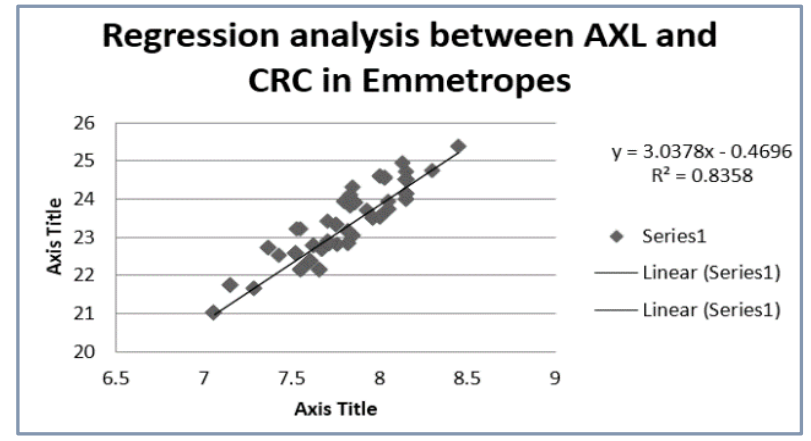

The regression analysis between AXL and CRC showed that an increase of 1 unit in the CRC showed an increase of AXL by $3.03 \mathrm{~mm}$ with an $\mathrm{R}^{2}$ of 0.83 , which means that there is a chance of $83.5 \%$ to explain this correlation, which is better when compared to the analysis between the reading in myopes and hypermetropes.

\section{Regression analysis between $A X L$ and CRC in Hypertropes}

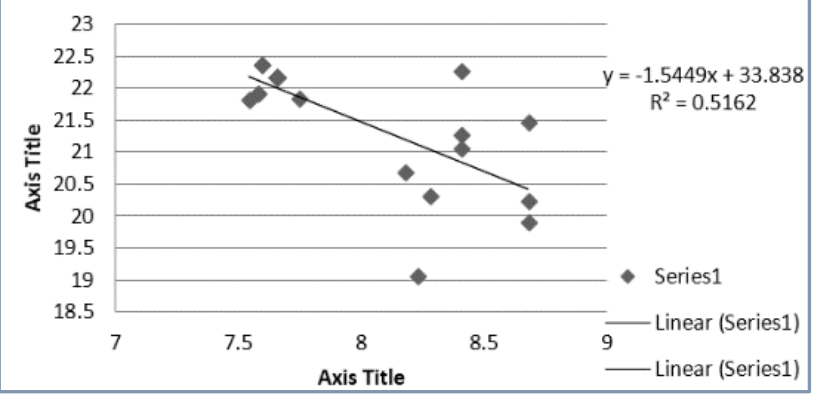

The regression analysis between CRC and AXL in hypertropes gave an $\mathrm{R}^{2}$ value of 0.51 , which shows that the correlation between the CRC and AXL could be explained only with a chance of $51.6 \%$. The observed change was that with an increase of 1 unit in the CRC the AXL was observed to change by $1.5 \mathrm{~m}$.

\section{DISCUSSION}

The distribution of AL/CRC has been reported in different populations and age groups. ${ }^{1,3,10,15}$ All of these studies have provided $\mathrm{AL} / \mathrm{CRC}$ values along with other biometric components. In the current study, we focused on the AL/CRC ratio and reported its association with refractive errors. A summary of other studies is presented in the table below. The reported mean values in different studies range from 2.9 to 3.1. These results revealed some interesting insights.

\begin{tabular}{|c|c|c|c|c|c|}
\hline Origin & $\mathbf{N}$ & Age (y) & AL/CRC & AL & CRC \\
\hline Singapore & 1.004 & 40 to 81 & 3.04 & 23.23 & 7.65 \\
\hline Myanmar & 444 & $40-49$ & 2.99 & 22.75 & 7.61 \\
\hline Myanmar & 463 & $50-59$ & 2.99 & 22.74 & 7.61 \\
\hline Myanmar & 342 & $60-69$ & 2.99 & 22.74 & 7.61 \\
\hline Myanmar & 249 & $>70$ & 2.97 & 2.73 & 7.65 \\
\hline Myanmar & 1498 & $40+$ & 2.99 & 22.76 & 7.62 \\
\hline $\begin{array}{l}\text { Mashhad, } \\
\text { Iran }\end{array}$ & 269 & $21-60$ & 3.10 & 23.60 & 7.6 \\
\hline Australia & 1765 & 5.5 to 8.4 & 2.906 & - & - \\
\hline UK & 373 & $17-30$ & 3.10 & - & - \\
\hline Spain & 583 & $20.32 \pm 2.82$ & 3.05 & - & - \\
\hline Jordan & 1093 & $17-40$ & 3.00 & - & - \\
\hline \multicolumn{6}{|c|}{$\begin{array}{c}\text { Table 1: Studies reporting Axial Length }(A L), \\
\text { Corneal Radius of Curvature (CRC) and AL/CRC } \\
\text { Origin N Age (y) AL/CRC }\end{array}$} \\
\hline
\end{tabular}

The mean AL in our study is $23.77 \mathrm{~mm}$. This study is similar to the value reported in Singapore study, which included Indians living in Singapore. The AL/RCC in our study is 2.98 , which is very similar to the value reported in the Myanmar study of rural population, which reported a mean value of 2.99. The value is also similar in the Shahroud eye study. ${ }^{16}$ which reported a value of 3.0. AL/CRC showed the strongest correlation with SE refractive error. $\mathrm{R}^{2}$ coefficients for AL/CRC were 0.8 . We found better correlation when compared to the Shahroud eye study, which reported a coefficient of 0.351 . Perhaps since our sample included a greater number of myopes, where the regression analysis is found to be more linear. Mean AL/CRC was 3.49 in eyes with myopia greater than $-5.0 \mathrm{D}$ in our study, which seems to be in agreement with the Shahroud eye study, which reported a value of 3.3D. 17

This value decreased linearly and reached a minimum of 2.65 in cases with hyperopia more than $2.0 \mathrm{D}$, which again is not so different from the values reported in the Shahroud eye study. ${ }^{17}$ Linear regression showed a shift of $14 \mathrm{D}$ in SE refractive error towards myopia with every 1 unit increase in AL/CRC $(\mathrm{P}<0.001)$ in our study. This value is similar to the Shahroud eye study, which reported and change of $12 \mathrm{D}$ towards myopia for every 1 unit increase in the AL/CRC. ${ }^{17}$

\section{ASSOCIATION OF AL, CRC AND REFRACTIVE ERRORS}

Grosvenor. ${ }^{8}$ was the first to suggest an association between AL/CRC and refractive errors. ${ }^{8}$ He pointed out the importance of this index, especially in myopes as in several other reports.18,19,20 Our findings further confirm Grosvenor's hypothesis. We found a linear increase in AL/CRC from high hyperopia toward high myopia. Every 1 unit of increase in AL/CRC was associated with approximately 14D of myopic shift with an R2 coefficient of 0.8. A similar finding was observed in the Shahroud eye study, where an increase of 0.1 unit in AXL/CRC leads to an increase with approximately 1.0D of myopic shift. This finding has been confirmed by other investigators as well. 8 


\section{STRONGER ASSOCIATION OF SE AND AXL/CRC}

The association between SE and AL/CRC was stronger than that with AL or CRC alone; this finding has been previously reported by Grosvenor. ${ }^{8}$ and the Shahroud eye study. ${ }^{17}$ Our findings indicate that refractive errors are a function of changes in AL and CRC. Major changes in each component can change the ratio and manifest as high refractive errors.

For example in high myopia, high AL is present and since emmetropization is disrupted, the cornea cannot compensate for changes in AL similar to that seen in the Shahroud Eye study. ${ }^{17}$ Overall, in light of results from different studies. ${ }^{8,10,11,12}$ chances of emmetropia are highest when the $\mathrm{AL} / \mathrm{CRC}$ ratio is close to 3 . Our study found the zone of emmetropization to be at 2.98. The Shahroud eye study reported this value to be 3.01.17 Any disturbance in this ratio, in any age group can be interpreted as a sign portending refractive errors. Children, in particular, a ratio that differs from 3 can be indicative of disruption in the emmetropization process and therefore assessment for amblyopia and anisometropia become important.

A change in the ratio during their growth can also be an index of whether they are towards or away from emmetropization. Although emmetropization is a slower process in adults, the fact that the $\mathrm{AL} / \mathrm{CRC}$ ratio remains constant becomes important in interpreting the pathogenesis of pathologic conditions. Although clinical application of the ratio fades in the presence of advanced clinical tests such as electrophysiological tests, retinal imaging, optical nerve head imaging, and optical coherence imaging, it is still an important predictive index for children at risk of progressive myopia and adults at risk of primary open angle glaucoma.

The linear regression equation showing that for every 1 unit increase in the ratio of Al and CRC will cause nearly a 14D shift towards myopia. The $\mathrm{R}^{2}$ of 0.867 shows that there is $86.7 \%$ chance that the variation of the spherical equivalent can be explained by the variation of the ratio between AL and CRC in the right eye. Similar findings have been observed in the LE where 1 unit rise in the ratio of AL and CRC leads to a shift of 15 diopters towards myopia. $\mathrm{R}^{2}$ coefficient of 0.839 shows that there is $83.9 \%$ chance of explaining the variation of the spherical equivalent with the variation of the ratio between $\mathrm{AL}$ and CRC. This finding is similar that observed in the RE.

The regression analysis between AXL and spherical equivalent showed that for an increase of 1 unit in the axial length was associated with a shift of 1.43D towards myopia. The $\mathrm{R}^{2}$ value was observed to be 0.69 , which means that this correlation could be explained with a $69.5 \%$ chance, which is less compared to the regression values between the ratio of AXL and CRC and the corresponding spherical equivalent values. The regression analysis done for the variations between axial length and spherical equivalent shoed an $\mathrm{R}^{2}$ coefficient of 0.694 which means a $69.4 \%$ chance exists to explain the interdependent variation of the variables. The R2 for mean CRC and spherical equivalent is XYZ.

This signifies that the variation is better correlating the ratio of the $\mathrm{AL}$ and $\mathrm{CRC}$ rather than their independent variations, although axial length correlates better than mean CRC. The linear regression between CRC and AXL in myopes $>5 \mathrm{D}$ showed that every 1 unit increase in CRC was associated with an increase in the axial length by $3.3 \mathrm{~mm}$ with an $\mathrm{R}^{2}$ of 0.604 indicating that there was a $60.4 \%$ chance to explain this relation. The radius of curvature ranging from 7.2 to 8.3.
The regression analysis between AXL and CRC showed that an increase of 1 unit in the CRC showed an increase of AXL by $3.03 \mathrm{~mm}$ with an $\mathrm{R}^{2}$ of 0.83 , which means that there is a chance of $83.5 \%$ chance to explain this correlation, which is better when compared to the analysis between the reading in myopes and hypermetropes. The regression analysis between CRC and AXL in hypertropes gave an $\mathrm{R}^{2}$ value of 0.51 , which shows that the correlation between the CRC and AXL could be explained only with a chance of $51.6 \%$. The observed change was that with an increase of 1 unit in the CRC, the AXL was observed to change by $1.5 \mathrm{~m}$.

The correlation between AXL/CRC and SE in this study was found to be better in emmetropes and myopes less than 5D. The correlation was found to be weak. This study observed that there is definite significant level of predictability in the change in the ratio of AXL and CRC and spherical equivalent with respect to each other in emmetropes and myopes < $5 \mathrm{D}$. Individual variations of AXL and CRC seem to be less important than their ratio in most instances. Also CRC has a lesser level of correlation when compared to the AXL. It can be inferred from this study that curvatural myopia has a lesser in the sample population than axial myopia.

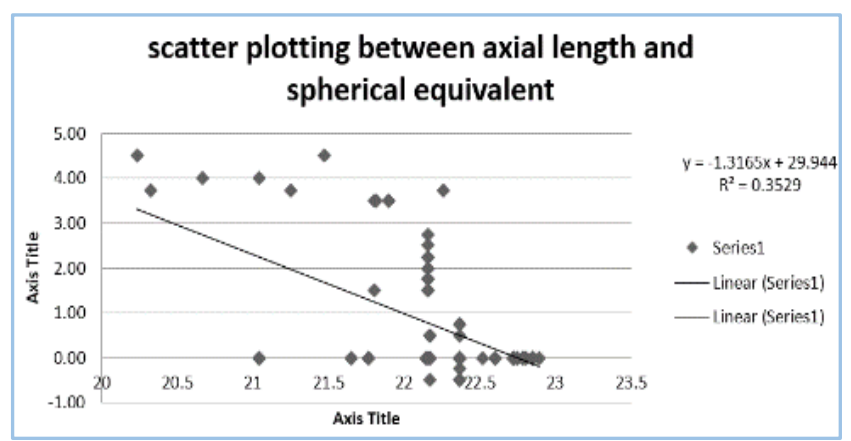

The above scatter plotting shows that with an R2 value of only 0.352 , there is only a $30 \%$ chance to explain the correlation between the axial length and the spherical equivalent within the range of the axial length between $20 \mathrm{~mm}$ and $23 \mathrm{~mm}$. This range is found to be closely correlated within the range of emmetropia where other values adjust to attain an optimum state of vision.

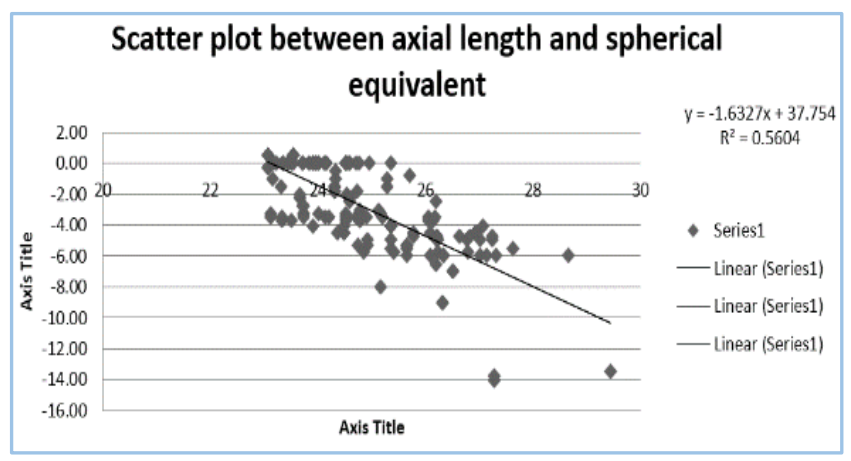

The above graph shows the scatter plot between axial between and spherical equivalent within the range axial length between $23 \mathrm{~mm}$ and $29 \mathrm{~mm}$. With an $\mathrm{R}^{2}$ of 0.560 , there is a $56 \%$ chance to explain the correlation between the axial length and the spherical equivalent in this range. With an increase in the axial length by $1 \mathrm{~mm}$, there is a corresponding value of the spherical equivalent by $1.6 \mathrm{D}$ towards myopia. We conclude 
that the ratio between axial length and corneal radius of curvature correlates better with the corresponding spherical equivalent than the individual values as such. What governs

\section{CONCLUSION}

Refractive error cannot be determined by a single optical component. It is the result of a combined interactive effect. The ratio of axial length and corneal radius of curvature seem to be a very reliable index of estimating the kind of resultant refracture error one might have. Axial length is the most influential factor in determining refraction. Radius curvature by itself did not not seem to have much of an effect on the resultant refractive error. In myopia due to increased axial length error can be corrected by flattening the cornea. This principle is employed in LASIK. But there is a corresponding decrease in the corneal thickness with higher error; therefore, LASIK cannot be used to correct higher degrees of myopia. The ratio of axial length and the radius of curvature of the cornea when kept near 2.98 can prove useful in correcting the refractive errors during refractive surgeries.

\section{REFERENCES}

1. Mallen EA, Gammoh Y, Al-Bdour M, et al. Refractive error and ocular biometry in Jordanian adults. Ophthalmic Physiol Opt 2005;25:302-309.

2. Yekta A, Fotouhi A, Hashemi H, et al. Relationship between refractive errors and ocular biometry components in carpet weavers. Iran J Ophthalmol 2010;22:45-54.

3. Warrier S, Wu HM, Newland HS, et al. Ocular biometry and determinants of refractive error in rural Myanmar: the Meiktila Eye Study. Br J Ophthalmol 2008;92:1591-1594.

4. Foster PJ, Broadway DC, Hayat S, et al. Refractive error, axial length and anterior chamber depth of the eye in British adults: the EPIC-Norfolk Eye Study. Br J Ophthalmol 2010;94:827-830.

5. Wickremasinghe S, Foster PJ, Uranchimeg D, et al. Ocular biometry and refraction in Mongolian adults. Invest Ophthalmol Vis Sci 2004;45:776-783.

6. Shufelt C, Fraser-Bell S, Ying-Lai M, et al. Refractive error, ocular biometry and lens opalescence in an adult population: the Los Angeles Latino Eye Study. Invest Ophthalmol Vis Sci 2005;46:4450-4460.

7. Ooi CS, Grosvenor T. Mechanisms of emmetropization in the aging eye. Optom Vis Sci 1995;72:60-66. this relation apart from the genetics and visual inputs remains to be answered and left for future studies to study.

8. Grosvenor T, Scott R. Role of the axial length/corneal radius ratio in determining the refractive state of the eye. Optom Vis Sci 1994;71:573-579.

9. Wu HM, Gupta A, Newland HS, et al. Association between stature, ocular biometry and refraction in an adult population in rural Myanmar: the Meiktila eye study. Clin Experiment Ophthalmol 2007;35:834-839.

10. González Blanco F, Sanz Ferńandez JC, Muńoz Sanz MA. Axial length, corneal radius and age of myopia onset. Optom Vis Sci 2008;85:89-96.

11. Goss DA, Jackson TW. Clinical findings before the onset of myopia in youth. I. Ocular optical components. Optom Vis Sci 1995;72:870-878.

12. Wong TY, Foster PJ, Ng TP, et al. Variations in ocular biometry in an adult Chinese population in Singapore: the Tanjong Pagar Survey. Invest Ophthalmol Vis Sci 2001;42:73-80.

13. Ojaimi E, Rose KA, Morgan IG, et al. Distribution of ocular biometric parameters and refraction in a population-based study of Australian children. Invest Ophthalmol Vis Sci. 2005;46:2748-2754.

14. He M, Huang W, Li Y, et al. Refractive error and biometry in older Chinese adults: the Liwan eye study. Invest Ophthalmol Vis Sci 2009;50:5130-5136.

15. Logan NS, Davies LN, Mallen EA, et al. Ametropia and ocular biometry in a UK University student population. Optom Vis Sci 2005;82:261-266.

16. Zadnik K, Mutti DO, Mitchell GL, et al.

17. Abrams D. Myopia. In: Duke -Elder's practice of refraction; 10th ed., Butterworth - Heinemann, Oxford 1993; p.53-65.

18. Jaffe NS, Jaffe MS, Jaffe GF. Intraocular lens implant. In: cataract surgery and its complications; 6th ed., Mosby-year book, USA 1999; p.162-75.

19. Stenstrom S. Investigation of the variation and the correlation of the optical elements of human eyes. Am J Optom Arch Am Acad Optom: 1948;25:438-51.

20. Hashemi H1, Khabazkhoob M, Miraftab M, et al. Axial length to corneal radius of curvature ratio and refractive errors. J Ophthalmic Vis Res 2013 Jul;8(3):220-6. 